\title{
Psycho-active Substances Use and Determining Factors Among Regular Undergraduate Students of Dire-Dawa University, Eastern Ethiopia
}

\author{
Gemechis Tesso Kumburi ${ }^{1, \text { * }}$, Atinafu Kebede Gelgile ${ }^{2}$, Bedasa Tessema Hatehu ${ }^{3}$, \\ Dagne Tafa Gemechu ${ }^{4}$ \\ ${ }^{1}$ School of Medicine, College of Medicine and Health Sciences, Dire Dawa University, Dire Dawa, Ethiopia \\ ${ }^{2}$ Department of Life Sciences, College of Natural and Computational Sciences, Dire Dawa University, Dire Dawa, Ethiopia \\ ${ }^{3}$ Department of Statistics, College of Natural and Computational Sciences, Dire Dawa University, Dire Dawa, Ethiopia \\ ${ }^{4}$ Department of Psychology, College of Social Science and Humanities, Dire Dawa University, Dire Dawa, Ethiopia
}

\section{Emailaddress:}

gemtesso2010@gmail.com (G. T. Kumburi), atnafukebede@yahoo.com (A. K. Gelgile), btesema2013@gmail.com (B. T. Hatehu), dgntf1999@gmail.com (D. T. Gemechu)

${ }^{*}$ Corresponding author

\section{To cite this article:}

Gemechis Tesso Kumburi, Atinafu Kebede Gelgile, Bedasa Tessema Hatehu, Dagne Tafa Gemechu. Psycho-active Substances Use and Determining Factors Among Regular Undergraduate Students of Dire-Dawa University, Eastern Ethiopia. Science Journal of Public Health . Vol. 5, No. 2, 2017, pp. 68-76. doi: 10.11648/j.sjph.20170502.13

Received: December 2, 2016; Accepted: December 15, 2016; Published: February 6, 2017

\begin{abstract}
Several studies indicate that use of psycho-active substances among Ethiopian youths is considerably rising particularly in universities. The use of psycho-active substances among youths can be harmful, leading to decreased academic performance, increased risk of exposure to sexually transmitted diseases, and psychiatric disorders such as lethargy, hopelessness and insomnia. The aim of this study was to investigate the magnitude and factors determining psycho-active substances use among regular undergraduate students of Dire-Dawa University. Cross-sectional study was conducted to explore the magnitude of self-reported psycho-active substance use and any association between these habits and the determinant factors among students of the Dire-Dawa University. Frequencies, proportion for categorical variables and crosstabulations were used for data summarization. Binary Bivariate and Multivariate Logistic Regression analyses were used to identify factors associated with substance. Bivariate analysis was done, and variables with p-value less than 0.05 were used in the multivariate logistic regression analysis. Odds Ratio and 95\% confidence intervals were also computed with the corresponding p-value. $64.3 \%$ of respondents used psycho-active substances in their life time. The top three psycho-active substances used in last twelve months were alcohol $(60 \%)$, khat $(59.9 \%)$ and tobacco $(56.5 \%)$. Through multivariate logistic regression analysis, being male, having peer influence, getting relief from stress, keeping alert while reading, using psychoactive substances (PAS) for recreational purpose, lacking of sufficient alternative means of recreation in the university campus, finding availability of PAS use centers around the university campus and using alcohol and cigarettes as a means of breaking the depression that ensues once the stimulation from khat has subsided significantly associated with PAS use. This study has revealed that psycho-active substances use among the undergraduate regular students of Dire Dawa University was higher than the findings of other similar studies conducted in public universities of Ethiopia. Being male, having peer influence, getting relief from stress, keeping alert while reading, using PAS for recreational purpose, lacking of sufficient alternative means of recreation in the university campus, finding availability PAS use centers around the university campus and using alcohol and cigarettes as a means of breaking the depression that ensues once the stimulation from khat has subsided were significantly associated with PAS use.
\end{abstract}

Keywords: Psycho-Active Substances Use, Khat, Alcohol, Tobacco Products, Cannabis Products 


\section{Introduction}

In developing countries the use of alcohol, khat, tobacco and cocaine has become one of the rising major public health and socio-economic problems in worldwide [1]. Even though substances use occurs in all segments of all societies, it is more spreading in an alarming rate among the young generation [2].

Khat is being chewed as a habit in some African countries such as Ethiopia, Somalia, Kenya, and Yemen. Moreover, the habit is now being introduced into different countries of the world [3]. In some Ethiopian communities, chewing khat is common and becoming an every-day drug [4]. There is a strong link between chewing khat, taking excess alcohol, unsaved sexual practice. This exposes people for HIV/AIDS [5-7].

Several studies indicate that the use of psycho-active substances among Ethiopian youths is rising considerably $[2,5,8,9]$. Nowadays, high school and college students are using alcohol and khat widely in Ethiopia [2]. However, illicit psycho-active substances such as heroin and cocaine were rarely used in Ethiopia [10].

Using alcohol, khat, tobacco and other psycho-active substances by youths are harmful. They make students to have decreased academic performance, to get HIV and other sexually transmitted diseases. Moreover, they could be unprotected to psychiatric disorders such as lethargy, hopelessness and insomnia [11]. According to the research done in Dire Dawa Administration, the excessive use of alcohol and other substances (such as alcohol, khat, and tobacco products) was identified as a main factor for the prevalence of HIV infection among youths [12].

Different factors are raised as determinants for the use of psycho-active substances among college and university students. Using alcohol, khat, tobacco and other psychoactive substances by youths are harmful. They make students to have decreased academic performance, to get HIV and other sexually transmitted diseases. Moreover, they could be unprotected to psychiatric disorders such as lethargy, hopelessness and insomnia. For example, a significant number of students consume khat to be alert and conscious through night. Especially, the students chew khat during the examination period [10]. Availability of substances, having friends and families who use substances were the commonly mentioned factors that influence substances use [13]. Besides, after the students get an opportunity to join university, they feel independent and become decision maker. These things gear them to peer-pressures to use drugs [11].

Of the young segment of Ethiopian population, college and university students are the most at risk of using alcohol, khat, tobacco, cocaine, shisha and other psycho-active substances [11]. Drinking alcohol and chewing khat was identified as a risk factor for HIV infection among students of Dire Dawa University [14]. Dire Dawa is one of the towns in Ethiopia where the use of khat, alcohol and tobacco products are common. Especially, khat is highly available in the town and it is commonly chewed by majority of the population.

In addition, though the use of alcohol, khat and cigarette have become common practices among high school and college/university students in Ethiopia, only few studies have assessed their magnitude and the associated factors. However, the factors associated with psycho-active substances use has not been investigated among students of Dire-Dawa University. Therefore, objective of this study was to investigate the prevalence and factors determining psychoactive substances use among regular undergraduate students of Dire-Dawa University.

\section{Methods}

This study was carried out in May, 2016 on regular undergraduate students of Dire-Dawa University in Ethiopia. Dire-Dawa University is found in Dire Dawa town, eastern part of Ethiopia. The university is located about $515 \mathrm{~km}$ far from Finfinnee (Addis Ababa). The University has a total of 10,728 regular undergraduate students enrolled in 33 academic departments in 2015/16 academic year. The study included students attending from Year 1 to year 5. Crosssectional study was conducted to explore the magnitude of self-reported psycho-active substance use and any association between these habits and the determinant factors among students of Dire-Dawa University.

The sample size was calculated, using the formula: $n=\frac{Z^{2} p(1-p)}{d^{2}}$

Where: $\mathrm{n}=$ the minimum required sample size, $\mathrm{p}=$ prevalence of psychoactive substances use and $d=$ the marginal error. Using $2.5 \%$ margin of error at $95 \%$ confidence level, the minimum required sample size was calculated to be 1239 . P was determined by the pre-test as 0.72 . The minimum required sample size was 1,239 students, representing $11.55 \%$ of the study population. The calculated sample size was proportionally distributed to each stratum (batch) found in all 33departments based on their enrolment size. The study participants from each batch were selected by using systematic random sampling technique.

Alcohol drinking, khat chewing and tobacco products use were used in the logistic regression model as dependent variables. Gender, age, religion, marital status, rural-urban background, year of study in the university, monthly income, parental educational status, dormitory-non-dormitory status and reported reasons of psycho-active substance (PAS) use that extracted from the questionnaire were used in the model as an independent variables. Moreover, khat chewing was considered to be a predictor for the use of alcohol and tobacco products.

A self-administered WHO Model Core Questionnaire, consisting of open and closed ended questions, to collect information on use of various Psychoactive Substances (PAS) was utilized by making important modifications on it. Pretesting of the questionnaire was undertaken on $5 \%$ of the respondents in order to check the clarity and appropriateness 
of the items included in the questionnaire.

In this study report, the term "Psycho-active substance" is utilized to refer substances that affect (stimulate or suppress) the normal functions of human nervous system. Psychoactive substance use in this study is defined as the use of alcohol, khat, tobacco products and others by Dire-Dawa University students in lifetime, in the past 12 months or in the past 30 days.

Finally, the collected data were sorted, coded and entered into SPSS computer software package version 20. Frequencies and proportion for categorical variables including cross-tabulations were used for data summarization. Binary Bivariate and Multivariate Logistic Regression analyses were used to identify factors associated with substance. Bivariate analysis was done, and variables with p-value less than 0.05 were used in the multiple logistic regression analysis. Odds Ratio (OR) and 95\% confidence intervals were also computed along with the corresponding $\mathrm{p}$ value.

With regard to the ethical considerations, this study was reviewed and approved by the Dire Dawa University Research review committee. The purpose and importance of the study were explained and written consent was obtained from each respondent. Hence, participation of the students in this study was voluntary. Appropriate measures were taken to ensure confidentiality of information both during and after data collection.

In order to assure quality of the data, data collectors were trained on how to scientifically select study participants, help the respondents on how to fill the questionnaire, and keep confidentiality of the collected information through questionnaire until they were submitted to the researchers.
Moreover, sample selection and data collection activities of data collectors were supervised by experienced researchers. Additionally, data entry was done by an expert at the College of Natural and Computational Sciences. Data cleaning, processing and analyses were done by consulting experienced Public Health researcher at College of Medicine and Health Sciences, Dire Dawa University.

\section{Results}

Out of 1,239 regular undergraduate Dire Dawa university students, selected as the study participant, 930 of them willingly filled the questionnaire. Fifteen filled questionnaires were discarded due to data incompleteness. Therefore, the final sample size included 915 regular undergraduate students, making the response rate of $73.85 \%$.

Six hundred and twenty (67.8\%) of the study participants were males. Among the study participants, 710 (77.6\%) were with age between twenty and twenty four. Four hundred eighty three $(52.8 \%)$ of the study participants were Orthodox Christians and $826(90.3 \%)$ of them were single. With regards to original residence, $608(66.4 \%)$ were from urban area, whereas $307(33.6 \%)$ of the respondents were from rural area. Majority of the study participants $(53.2 \%)$ reported that their monthly income was between 150 to 500 birr. Parental education of the respondents revealed that $17.6 \%$ mothers and $11.3 \%$ fathers were reported to be illiterate; with only $18.2 \%$ mothers and $40.97 \%$ fathers were graduated from college/university. On the other hand, 667 $(72.9 \%)$ study participants were dormitory users, while 248 (27.1\%) were non-dormitory students (table 1$)$.

Table 1. Socio-demographic characteristics of study participants (Dire Dawa University regular undergraduate students) by sex ( $n=915$ ), May 2016.

\begin{tabular}{|c|c|c|c|}
\hline \multirow{2}{*}{ Characteristics } & \multicolumn{2}{|l|}{ Sex } & \multirow{2}{*}{ Total n (\%) } \\
\hline & Male n (\%) & Female n (\%) & \\
\hline \multicolumn{4}{|c|}{ Age group (in Years) } \\
\hline $15-19$ & $44(7.1 \%)$ & $73(24.7 \%)$ & $117(12.8 \%)$ \\
\hline $20-24$ & $502(81 \%)$ & $208(70.5 \%)$ & $710(77.6 \%)$ \\
\hline $25-30$ & $74(11.8 \%)$ & $14(4.7 \%)$ & $88(9.5 \%)$ \\
\hline Total & $620(67.8 \%)$ & $295(32.2 \%)$ & $915(100 \%)$ \\
\hline \multicolumn{4}{|l|}{ Religion } \\
\hline Orthodox & $300(48.4 \%)$ & $183(62 \%)$ & $483(52.8 \%)$ \\
\hline Muslim & $183(29.5 \%)$ & $43(14.6 \%)$ & $226(24.7 \%)$ \\
\hline Protestant & $100(16.1 \%)$ & $49(16.6 \%)$ & $149(16.3 \%)$ \\
\hline Waqefannaa & $22(3.5 \%)$ & $9(3.1 \%)$ & $31(3.4 \%)$ \\
\hline Others & $15(2.4 \%)$ & $11(3.7 \%)$ & $26(2.8 \%)$ \\
\hline \multicolumn{4}{|l|}{ Marital Status } \\
\hline Single & $571(92.1 \%)$ & $255(86.4 \%)$ & $826(90.3 \%)$ \\
\hline Married & $25(4 \%)$ & $20(6.8 \%)$ & $45(4.9 \%)$ \\
\hline Divorced & $24(3.9 \%)$ & $20(6.8 \%)$ & $44(4.8 \%)$ \\
\hline \multicolumn{4}{|c|}{ Original residence } \\
\hline Rural & $217(35 \%)$ & $90(30.5 \%)$ & $307(33.6 \%)$ \\
\hline Urban & $403(65 \%)$ & $205(69.5 \%)$ & $608(66.4 \%)$ \\
\hline \multicolumn{4}{|c|}{ Monthly income (Birr) } \\
\hline$<1500$ & $102(16.5 \%)$ & $38(12.9 \%)$ & $140(15.3 \%)$ \\
\hline-500 & $318(51.3 \%)$ & $169(57.3 \%)$ & $487(53.2 \%)$ \\
\hline$>500$ & $200(32.3 \%)$ & $88(29.8 \%)$ & $288(31.5 \%)$ \\
\hline \multicolumn{4}{|c|}{ Year of study in the university } \\
\hline Year I & $152(24.5 \%)$ & $110(37.3 \%)$ & $262(28.6 \%)$ \\
\hline Year II & $182(29.4 \%)$ & $70(23.7 \%)$ & $252(27.5 \%)$ \\
\hline Year III & $135(21.8 \%)$ & $63(21.4 \%)$ & $198(21.6 \%)$ \\
\hline
\end{tabular}




\begin{tabular}{llll}
\hline \multirow{2}{*}{ Characteristics } & Sex & Female n (\%) & Total n (\%) \\
\cline { 2 - 4 } & Male n (\%) & $22(7.5 \%)$ & $84(9.2 \%)$ \\
\hline Year IV & $62(10 \%)$ & $30(10.2 \%)$ & $119(13 \%)$ \\
Year V & $89(14.4 \%)$ & $120(40.7 \%)$ & $433(47.3 \%)$ \\
Institute of Technology & & $50(16.9 \%)$ & $160(17.5 \%)$ \\
Business and Economics & $313(50.5)$ & $14(4.7 \%)$ & $68(7.4 \%)$ \\
Medicine and Health Sciences & $110(17.7 \%)$ & $71(24.1 \%)$ & $151(16.5 \%)$ \\
Natural and Computational Sciences & $54(8.7 \%)$ & $30(10.2 \%)$ & $80(8.7 \%)$ \\
Social science and Humanities & $80(12.9 \%)$ & $10(3.4 \%)$ & $23(2.5 \%)$ \\
Law & $50(8.1 \%)$ & & $161(17.6 \%)$ \\
Mother's Educational level & $13(2.1 \%)$ & $38(12.9 \%)$ & $330(38.06 \%)$ \\
Illiterate & & $97(32.9 \%)$ & $256(25.9 \%)$ \\
Primary & $123(19.9 \%)$ & $102(34.5 \%)$ & $168(18.4 \%)$ \\
Secondary & $233(37.6 \%)$ & $58(19.7 \%)$ & $103(11.3 \%)$ \\
College/University & $154(24.9 \%)$ & & $193(21.1 \%)$ \\
Father's Educational level & $110(17.8 \%)$ & $24(8.1 \%)$ & $244(26.63 \%)$ \\
Illiterate & & $50(16.9 \%)$ & $375(40.97 \%)$ \\
Primary & $79(12.7 \%)$ & $70(23.7 \%)$ & $667(72.9 \%)$ \\
Secondary & $143(23.1 \%)$ & $151(51.2 \%)$ & $248(27.1 \%)$ \\
College/University & $174(28.1 \%)$ & & \\
When the respondent live & $224(36.1 \%)$ & $215(72.9 \%)$ & $80(27.1 \%)$ \\
In University campus/Dormitory & & & \\
Out of campus/Non-dormitory & $452(72.9 \%)$ & $168(27.1 \%)$ & \\
\hline
\end{tabular}

Among the 915 students, $64.3 \%$ of them responded that they had ever used psycho-active substance in their life time. Accordingly, 432 (69.7\%) males and 156 (52.9\%) females used psycho-active substances (PAS) in their life time. This revealed that male students were more PAS users than female students of Dire Dawa University (table 2). The top three psycho-active substances used in last twelve months by Dire
Dawa University regular undergraduate students were alcohol (60\%), khat (59.9\%) and tobacco (56.5\%). Though relatively smaller in proportion, $15.9 \%$ of the study respondents had ever used cannabis products in last 12 months. Similarly, the prevalence of alcohol, khat, tobacco and cannabis products use in past thirty days was $60 \%$, $59.6 \%, 41.2 \%$ and $13.7 \%$ respectively.

Table 2. Prevalence of psychoactive substances use among Dire Dawa university regular undergraduate students by sex, May 2016

\begin{tabular}{|c|c|c|c|c|}
\hline \multirow[t]{2}{*}{ Status of psycho-active substances use } & & \multicolumn{3}{|l|}{ Sex } \\
\hline & & Male n (\%) & Female n (\%) & Total n (\%) \\
\hline \multirow{2}{*}{ Ever use of psycho-active substance(s) } & Yes & $432(69.7 \%)$ & $156(52.9 \%)$ & $588(64.3 \%)$ \\
\hline & No & $188(30.3 \%)$ & $139(47.1 \%)$ & $327(35.7 \%)$ \\
\hline \multicolumn{5}{|l|}{ Chewing Khat } \\
\hline \multirow{2}{*}{ Chewed In last 12 months } & Yes & $406(65.5 \%)$ & $142(48.1 \%)$ & $548(59.9 \%)$ \\
\hline & No & $214(34.5 \%)$ & $153(51.9 \%)$ & $367(40.1 \%)$ \\
\hline Chewed in past 30 days & Yes & $403(65 \%)$ & $142(48.1 \%)$ & $545(59.6 \%)$ \\
\hline \multicolumn{5}{|l|}{ Alcohol Drinking } \\
\hline \multirow{2}{*}{ Drunk in last 12 months } & Yes & $378(61 \%)$ & $171(58 \%)$ & $549(60 \%)$ \\
\hline & No & $241(38.9 \% 0$ & $124(42 \%)$ & $365(39.9 \%)$ \\
\hline \multirow{2}{*}{ Drunk in past 30 days } & Yes & $355(57.3 \%)$ & $147(49.8 \%)$ & $502(54.9 \%)$ \\
\hline & No & $265(42.7 \%)$ & $148(50.2 \%)$ & $413(45.1 \%)$ \\
\hline \multicolumn{5}{|c|}{ Smoking, chewing or sniffing tobacco products (cigarette, shisha, chewable tobacco) } \\
\hline Used in last 12 months & Yes & $297(47.9 \%)$ & $101(34.2 \%)$ & $398(43.5 \%)$ \\
\hline Used in past 30 days & No & $338(54.5 \%)$ & $200(67.8 \%)$ & $538(58.8 \%)$ \\
\hline \multicolumn{5}{|c|}{ Using cannabis products (Marijuana, Hashish, Ganja) } \\
\hline \multirow{2}{*}{ Used in last 12 months } & Yes & $107(17.3 \%)$ & $38(12.9 \%)$ & $145(15.9 \%)$ \\
\hline & No & $512(82.7 \%)$ & $257(87.1 \%)$ & $769(84.1 \%)$ \\
\hline \multirow{2}{*}{ Used in past 30 days } & Yes & $93(15 \%)$ & $32(10.8 \%)$ & $125(13.7 \%)$ \\
\hline & No & $527(85 \%)$ & $263(89.2 \%)$ & $790(86.3 \%)$ \\
\hline
\end{tabular}

Socio-demographic and behavioral factors assumed to predict khat chewing in past year were assessed using logistic regression (table 3). Multivariate logistic regression analysis results indicated that being male was positively associated with khat use in past twelve months [adjusted odds ratio $(\mathrm{AOR})=1.19,95 \%$ $\mathrm{CI}=(0.80,4.76)]$. Having a friend who chews khat was significantly correlated to khat chewing in past year among Dire Dawa University regular undergraduate students $[\mathrm{AOR}=1.1$, $95 \% \mathrm{CI}=(0.68,3.77)]$. Like-wise, getting relief from stress $[\mathrm{AOR}=1.14,95 \% \mathrm{CI}=(0.65,2.00)]$ and keeping alert while reading $[\mathrm{AOR}=1.51,95 \% \mathrm{CI}=(0.90,2.87)]$ were positively associated with khat chewing in past 12 months. 
Table 3. Socio-demographic and behavioural factors predicting khat chewing within the last 12 months among regular undergraduate students of Dire Dawa University, May 2016

\begin{tabular}{|c|c|c|c|c|}
\hline \multirow{2}{*}{ Factor } & & \multicolumn{2}{|c|}{ Chewed khat in past 12 months } & \multirow{2}{*}{ Adjusted OR (95\% CI) } \\
\hline & & Yes n $(\%)$ & No n (\%) & \\
\hline \multirow{2}{*}{ Sex } & Male & $406(74.1 \%)$ & $214(58.3)$ & $1.19(0.80,4.76)^{*}$ \\
\hline & Female & $142(25.9 \%)$ & $153(41.7 \%)$ & 1 (Reference) \\
\hline \multirow{2}{*}{ Original residence } & Urban & $364(66.4 \%)$ & $244(66.5 \%)$ & $0.73(0.49,1.1)$ \\
\hline & Rural & $184(33.6)$ & $123(33.6 \%)$ & 1 (Reference) \\
\hline \multirow{2}{*}{ Peer influence } & Yes & $350(63.9 \%)$ & $198(36.1 \%)$ & $1.1(0.68,3.77)^{*}$ \\
\hline & No & $53(14.4 \%)$ & $314(85.6 \%)$ & 1 (Reference) \\
\hline \multirow{2}{*}{ To get relief from stress } & Yes & $346(63.1 \%)$ & $202(36.9 \%)$ & $1.14(0.65,2.00)^{*}$ \\
\hline & No & $36(9.8 \%)$ & $331(90.2 \%)$ & 1 (Reference) \\
\hline \multirow{2}{*}{ To keep alert while reading } & Yes & $291(53.1 \%)$ & $257(46.9 \%)$ & $1.51(0.90,2.87)^{*}$ \\
\hline & No & $48(13.1 \%)$ & $319(86.9 \%)$ & 1 (Reference) \\
\hline \multirow{2}{*}{ For recreational purpose } & Yes & $290(52.9 \%)$ & $258(47.1 \%)$ & $2.75(0.94,7.28)^{*}$ \\
\hline & No & $59(16.1 \%)$ & $308(83.9 \%)$ & 1 (Reference) \\
\hline \multirow{2}{*}{$\begin{array}{l}\text { Lack of sufficient alternative means of recreation in the university } \\
\text { campus }\end{array}$} & Yes & $279(50.9 \%)$ & $269(49.1 \%)$ & $1.37(0.71,5.65)^{*}$ \\
\hline & No & $41(11.2 \%)$ & $336(88.8 \%)$ & 1 (Reference) \\
\hline \multirow{2}{*}{ Availability of PAS around the university campus } & Yes & $205(37.4 \%)$ & $343(62.6 \%)$ & $0.87(0.45,1.59)$ \\
\hline & No & $39(10.6 \%)$ & $328(89.4 \%)$ & 1 (Reference) \\
\hline \multirow{2}{*}{ Availability of PAS use centre around the university campus } & Yes & $345(63 \%)$ & $203(37 \%)$ & $1.28(0.71,2.32)^{*}$ \\
\hline & No & $41(11.2 \%)$ & $326(88.8 \%)$ & 1 (Reference) \\
\hline \multirow{2}{*}{$\begin{array}{l}\text { Perception that khat use can help to improve academic } \\
\text { achievement }\end{array}$} & Yes & $343(62.6 \%)$ & $205(37.4 \%)$ & $2.18(1.12,4.28)^{*}$ \\
\hline & No & $64(17.4 \%)$ & $303(82.6 \%)$ & 1 (Reference) \\
\hline
\end{tabular}

*Variables which were significant in the multivariate analysis $(\mathrm{P}<0.05)$.

Lacking sufficient alternative means of recreation in the university campus was found as a significant correlate to khat chewing in past year $[\mathrm{AOR}=1.37,95 \% \mathrm{CI}=(0.71,5.65)]$ so that using khat as the means of recreation was positively associated with khat chewing in past 12 months among Dire Dawa University regular undergraduate students $[\mathrm{AOR}=$ $2.75,95 \%$ CI $=(0.94,7.28)]$. Similarly, availability of psycho-active substances use centre around the university campus was identified as significant predictor of khat chewing in past twelve months $[\mathrm{AOR}=1.28,95 \% \mathrm{CI}=$
$(0.71,2.32)]$. Table 3also displays that students who perceived that khat chewing can help to improve academic achievement, had the odds of 2-folds increase to use khat in past year $[\mathrm{AOR}=2.18,95 \% \mathrm{CI}=(1.12,4.28)]$.

Table 4 shows the socio-demographic and behavioral factors assumed to predict alcohol drinking in the last 12 months among regular undergraduate students of Dire Dawa University. Accordingly, students from urban used alcohol 1.35 times more likely than who were from rural area $(95 \%$ $\mathrm{CI}=0.93,1.95)$.

Table 4. Socio-demographic and behavioural factors predicting alcohol drinking in the last 12 months among regular students of Dire Dawa University, May 2016.

\begin{tabular}{|c|c|c|c|c|}
\hline \multirow{2}{*}{ Factor } & & \multicolumn{2}{|c|}{ Drunk Alcohol past 12 months } & \multirow{2}{*}{ Adjusted OR (95\%CI) } \\
\hline & & Yes n $(\%)$ & No n (\%) & \\
\hline \multirow{2}{*}{ Sex } & Male & $378(68.9 \%)$ & $171(31.1 \%)$ & $0.89(0.61,1.31)$ \\
\hline & Female & $241(66 \%)$ & $124(34 \%)$ & 1 (Reference) \\
\hline \multirow{2}{*}{ Original residence } & Urban & $384(69.9 \%)$ & $223(61.1 \%)$ & $1.35(0.93,1.95)^{*}$ \\
\hline & Rural & $165(30.1 \%)$ & $142(38.9 \%)$ & 1 (Reference) \\
\hline \multirow{2}{*}{ Peer influence } & Yes & $344(62.7 \%)$ & $205(37.3 \%)$ & $1.98(0.66,3.47)^{*}$ \\
\hline & No & $45(12.3 \%)$ & $320(87.7 \%)$ & 1 (Reference) \\
\hline For recreational purpose & No & $54(14.8 \%)$ & $311(85.2 \%)$ & 1 (Reference) \\
\hline \multirow{2}{*}{ To get relief from stress } & Yes & $179(32.6 \%)$ & $370(67.4 \%)$ & $0.44(0.27,0.73)$ \\
\hline & No & $36(9.9 \%)$ & $329(90.1 \%)$ & 1 (Reference) \\
\hline \multirow{2}{*}{$\begin{array}{l}\text { Lack of sufficient alternative means of recreation in the university } \\
\text { campus }\end{array}$} & Yes & $289(52.6 \%)$ & $260(47.4 \%)$ & $2.56(0.56,6.87)^{*}$ \\
\hline & No & $50(13.7 \%)$ & $315(86.3 \%)$ & 1 (Reference) \\
\hline \multirow{2}{*}{ Availability of PAS use centre around the university campus } & Yes & $345(62.8 \%)$ & $204(37.2 \%)$ & $2.42(0.97,6.67)^{*}$ \\
\hline & No & $40(11 \%)$ & $325(89 \%)$ & 1 (Reference) \\
\hline Used khat within past 12 months & No & $126(34.5 \%)$ & $239(65.5 \%)$ & 1 (Reference) \\
\hline
\end{tabular}

*Variables which were significant in the multivariate analysis $(\mathrm{P}<0.05)$.

Similarly, table 4 also shows that students who had chewed khat in last year had the odds of 3 -folds increase to drink alcohol in last twelve months $[\mathrm{AOR}=3.1,95 \% \mathrm{CI}=(0.96$,
12.14)]. Moreover, having peer influence was found to be a significant predicting factor of alcohol drinking among the study participants $[\mathrm{AOR}=1.98,95 \% \mathrm{CI}=(0.66,3.47)]$. On 
the other hand, using alcohol as a means of entertainment was found as a significant factor associated with alcohol drinking in past 12 months $[\mathrm{AOR}=1.81,95 \% \mathrm{CI}=(0.53$, 4.23)]. This was in line with multiple logistic analysis result that showed that lack of sufficient alternative means of recreation in the university campus was positively associated with alcohol drinking in past 12 months $[\mathrm{AOR}=2.56,95 \%$ $\mathrm{CI}=(0.56,6.87)]$. In addition, availability of PAS use centre around the university campus was identified as a factor that strongly and positively associated with alcohol drinking in past twelve months $[\mathrm{AOR}=2.42,95 \% \mathrm{CI}=(0.97,6.67)]$.

Table 5 shows that male students were more likely to use tobacco as compared to female students $[\mathrm{AOR}=1.82,95 \%$ $\mathrm{CI}=(0.58,5.15)]$. Those students whose friends use tobacco were 1.96 times more likely to use tobacco as compared to their counterpart $[\mathrm{AOR}=1.96,95 \% \mathrm{CI}=(0.66,4.42)]$. Similarly, students who had used khat in past 12 months had the odds of 3 -folds increase to use tobacco in past twelve months $[\mathrm{AOR}=3.70,95 \% \mathrm{CI}=(0.66,9.15)]$.

Table 5. Socio-demographic and behavioural factors predicting tobacco use in the last 12 months among regular undergraduate students of Dire Dawa University, May 2016.

\begin{tabular}{|c|c|c|c|c|}
\hline \multirow{2}{*}{ Factor } & & \multicolumn{2}{|c|}{ Used tobacco past 12 months } & \multirow{2}{*}{ Adjusted OR (95\% CI) } \\
\hline & & Yes n (\%) & No n (\%) & \\
\hline \multirow{2}{*}{ Sex } & Male & $297(74.6 \%)$ & $101(25.4 \%)$ & $1.82(0.58,5.15)^{*}$ \\
\hline & Female & $323(62.5 \%)$ & $194(37.5 \%)$ & 1 (Reference) \\
\hline \multirow{2}{*}{ Peer influence } & Yes & $245(61.6 \%)$ & $153(38.4 \%)$ & $1.96(0.66,4.42)^{*}$ \\
\hline & No & $98(19 \%)$ & $419(81 \%)$ & 1 (Reference) \\
\hline \multirow{2}{*}{ Recreational purpose } & Yes & $232(58.3 \%)$ & $166(41.7 \%)$ & $0.76(0.51,1.14)$ \\
\hline & No & $117(22.6 \%)$ & $400(77.4 \%)$ & 1 (Reference) \\
\hline \multirow{2}{*}{ To get relief from stress } & Yes & $234(58.8 \%)$ & $164(41.2 \%)$ & $1.40(0.43,2.65)^{*}$ \\
\hline & No & $51(9.9 \%)$ & $466(90.1 \%)$ & 1 (Reference) \\
\hline \multirow{2}{*}{ Lack of sufficient alternative means of recreation in DDU } & Yes & $220(55.3 \%)$ & $178(44.7 \%)$ & $0.44(0.29,0.66)$ \\
\hline & No & $90(17.4 \%)$ & $427(82.6 \%)$ & 1 (Reference) \\
\hline \multirow{2}{*}{ Availability of the PAS around DDU } & Yes & $165(41.5 \%)$ & $233(58.5 \%)$ & $0.45(0.29,0.69)$ \\
\hline & No & $79(15.3 \%)$ & $438(84.7 \%)$ & 1 (Reference) \\
\hline \multirow{2}{*}{ Availability of PAS use centre around DDU } & Yes & $223(56 \%)$ & $175(44 \%)$ & $1.27(0.81,1.99)^{*}$ \\
\hline & No & $69(13.3 \%)$ & $448(86.7 \%)$ & 1 (Reference) \\
\hline \multirow{2}{*}{ Chewed khat past 12 months } & Yes & $362(91 \%)$ & $36(9 \%)$ & $3.70(0.66,9.15)^{*}$ \\
\hline & No & $186(36 \%)$ & $331(64 \%)$ & 1 (Reference) \\
\hline
\end{tabular}

*Variables which were significant in the multivariate analysis $(\mathrm{P}<0.05)$.

Getting relief from stress $[\mathrm{AOR}=1.40,95 \% \mathrm{CI}=(0.43$, $2.65)]$ and availability of PAS use centre around the university campus $[\mathrm{AOR}=1.27,95 \% \mathrm{CI}=(0.81,1.99)]$ were significantly associated with tobacco use among regular undergraduate students of Dire Dawa University (table 5).

\section{Discussion}

The result of this study reveals that the magnitude of psycho-active substances (PAS) use among the regular undergraduate students of Dire Dawa University was very high. The overall life time PAS use was (64.3\%). This finding was almost similar to that of Eldoret Kenya as the life time PAS use among college students in Eldoret, western Kenya was reported to be $69.8 \%$ [16]. However, the life time PAS use among Dire Dawa University students was higher than similar studies done among public university students of Ethiopia, including Hawassa University (53.6\%), Axum University (49.5\%) and Debre Markos University (48.4\%) [2, $12,16]$.

This study identified that the top three PAS used last 12 months were alcohol (60\%), khat (59.9\%) and tobacco products $(43.5 \%)$. This was in line with the other studies conducted in Mekelle University, Axum University, Debre Markos University, Hawassa University and Addis Ababa University [2, 12, 16-18]. Our study indicates that the last year and current alcohol drinking prevalence were $60 \%$ and
$45 \%$ respectively. Consistently, similar study conducted at Axum University reported last year and current alcohol drinking as $34.5 \%$ and $32.8 \%$ respectively [2]. In accordance to this, the findings of our study indicate that $55.3 \%$ of those students who used PAS in their life time had started it before joining the University.

The past 12 months and current khat use among the regular undergraduate students of Dire Dawa University (DDU) were $59.9 \%$ and $59.6 \%$ respectively. This indicates that khat chewing was equivalently prevalent as alcohol. As compared to finding of similar studies from Axum University (past 12 months and current khat chewing were $28.7 \%$ and $27.9 \%$ respectively), Debre Markos University (past 12 months and current khat chewing were $30.8 \%$ and $28.1 \%$ respectively) and Addis Ababa University (past 12 months and current khat chewing were $7 \%$ and $4 \%$ respectively), the reported past 12 months and current prevalence of khat chewing among regular undergraduate students of Dire Dawa University was significantly very higher $[2,18,19]$. This might be due to the reason that the eastern part of Ethiopia is the largest producer of khat for export as well as for national consumption [20]. Similarly, these findings were in line with studies done among college and high school students of Jazan region, Saudi Arabia [21]. On the other hand, the past 12 months and current khat chewing among DDU regular undergraduate students were significantly higher than the prevalence reported from preparatory school students in Bale Zone, 
South-eastern Ethiopia and College students in Bahir Dar town. The last year and current khat chewing among preparatory students of Bale Zone were $26.7 \%$ and $17.5 \%$ respectively [22]. Whereas, last year and current khat chewing among college students in Bahir Dar town were $16.9 \%$ and $12.9 \%$ respectively [23]. This difference might be due to the reason that university students are relatively far from parents and relatives than preparatory or local college students; so that they are less controlled from being exposed to PAS use, particularly khat.

In this study, the third most commonly prevalent PAS was use of tobacco products like cigarette, shisha and chewable tobacco with past year and current prevalence $43.5 \%$ and $41.2 \%$ respectively. This was also in line with findings reported from Mekelle University, Axum University, Debre Markos University, Hawassa University and Addis Ababa University $[2,12,16-18]$. This might be due to that alcohol and cigarettes are commonly used to break the depression that ensues once the stimulation from khat has subsided. In a similar manner, a report among Somali khat chewers in London indicated that 60 percent of chewers also smoked [24]. In addition, availability of cigarette in shops found near the university campus, in cheaper price than that of alcohol and khat or availability of substance use centers where the students can get shisha around the university campus, might have contributed for the as such prevalence of use of tobacco products among DDU regular undergraduate students.

Although relatively lowest in magnitude, as compared to alcohol, khat and tobacco products, this study reveals that DDU regular undergraduate students had used cannabis products like Marijuana, Hashish and Ganja. The past year and current prevalence of use of cannabis products were $15.9 \%$ and $13.7 \%$ respectively. The finding of the present study was in line with that of Hawassa University students in which past year and current prevalence were reported to be $2.2 \%$ and $0.3 \%$ respectively [12]. The reason why the use of this illicit drug was reported might be due to cultivation of cannabis plant on a small scale in the country in a way that is undetectable to authorities.

Being male was significantly increased the odds of chewing khat by 1.19 folds [Adjusted OR $=1.19,95 \% \mathrm{CI}=$ $(0.80,4.76)]$ and to use tobacco products by 1.82 folds [Adjusted OR $=1.82,95 \% \mathrm{CI}=(0.58,5.15)]$ respectively as compared to being female. This might be due to cultural influences that discourage females from using PAS [23].

Being from urban area [Adjusted OR $=1.35,95 \% \mathrm{CI}=$ $(0.93,1.95)]$, used khat in past 12 months [Adjusted OR = $3.1,95 \%$ CI $=(0.96,12.14)]$, having peer influence [Adjusted OR $=1.98,95 \% \mathrm{CI}=(0.66,3.47)$ ], PAS use for recreational purpose [Adjusted OR $=1.81,95 \% \mathrm{CI}=(0.53$, $4.23)$ ], lacking sufficient alternative means of recreation in the university campus[Adjusted $\mathrm{OR}=2.56,95 \% \mathrm{CI}=(0.56$, 6.87)] and availability of PAS use centre around the university campus[Adjusted OR $=4.42,95 \% \mathrm{CI}=(0.97$, 6.67)] were significantly associated with alcohol drinking in past 12 months among DDU regular undergraduate students. These finding were consistent with similar reports from high schools in Harar town [24] and Addis Ababa University [18].

Having perception that khat use can help to improve academic achievement [Adjusted $\mathrm{OR}=2.18,95 \% \mathrm{CI}=(1.12$, 4.28)], PAS use for recreational purpose[Adjusted $\mathrm{OR}=2.75$, $95 \% \mathrm{CI}=(0.94,7.28)]$, lacking of sufficient alternative means of recreation in the university campus[Adjusted OR = $1.37,95 \% \mathrm{CI}=(0.71,5.65)]$ and availability of PAS use centre around the university campus[Adjusted OR $=1.28$, $95 \% \mathrm{CI}=(0.71,2.32)]$, being male $[$ Adjusted $\mathrm{OR}=1.19$, $95 \% \mathrm{CI}=(0.80,4.76)]$, having peer influence $[\mathrm{AOR}=1.1$, $95 \% \mathrm{CI}=(0.68,3.77)]$ and getting relief from stress $[\mathrm{AOR}=$ $1.14,95 \% \mathrm{CI}=(0.65,2,00)]$ were significantly associated with khat chewing in past 12 months. These were consistent with other similar research conducted at Hawassa University [12], Axum University [2] and Debre Markos University [19].

Similarly, being male [Adjusted OR $=1.82,95 \% \mathrm{CI}=$ $(0.58,5.15)]$, peer influence $[\mathrm{AOR}=1.96,95 \% \mathrm{CI}=(0.66$, $4.42)$, getting relief from stress $[\mathrm{AOR}=1.40,95 \% \mathrm{CI}=$ $(0.43,2.65)]$, and availability of PAS use centre around the university campus $[\mathrm{AOR}=1.27,95 \% \mathrm{CI}=(0.81,1.99)]$ and chewed khat last year $[\mathrm{AOR}=3.70,95 \% \mathrm{CI}=(0.66,9.15)$ ] were found as significant predicting factors of using tobacco products in past 12 months. These were in line with the similar studies $[2,18,19]$.

\section{Limitations of the Study}

The main limitation of this study is related to its design. Because, it is impossible to establish trends and causality between PAS use and the potential risk factors by using cross-sectional study design. In addition to this, the data collection tool that has utilized in the current study has its own limitation also. This is due to the reason that self reported data collected by structured, self-administered questionnaire is vulnerable to recall-bias, over-reporting or under-reporting.

\section{Conclusions}

This study has revealed that psycho-active substances use among the undergraduate regular students of Dire Dawa University was higher than the findings of other similar studies conducted in public universities of Ethiopia. Being male, having peer influence, getting relief from stress, keeping alert while reading, using PAS for recreational purpose, lacking of sufficient alternative means of recreation in the university campus, finding availability PAS use centers around the university campus and using alcohol and cigarettes as a means of breaking the depression that ensues once the stimulation from khat has subsided were significantly associated with PAS use among the Dire Dawa University regular undergraduate students.

\section{Recommendations}

Up on understanding the factors associated with the 
psycho-active substances use, the Dire Dawa University needs to design and implement comprehensive anti-psychoactive substance use interventions that prevent multiple risk factors among students. Consistently, the Federal Ministry of Education of Ethiopia needs to focus and integrate education about substances use and related ill effects into the curricula of primary and secondary schools.

\section{Acknowledgements}

We deeply express our gratefulness to Dire Dawa University for financial support. Our special thanks and sincere appreciation also go to all concerned offices of the university, supervisors, data collectors, data sorter \& feeders and study participants. We would like to thank Mr. Hussen Mohammed (MPH in Epidemiology) for his support and guidance in data analysis. Our deepest gratitude also goes to Dr. Alemayehu Zewdie (PhD) and Mr. Markos Medhin for their crucial contribution in providing comments on the manuscript with regard to the English language utilization.

\section{References}

[1] Odejide AO: Status of drug use/abuse in Africa: A review. International Journal of Mental Health 2006, 4:87-102.

[2] Gebreslassie M, Feleke A, Melese T: Psychoactive substances use and associated factors among Axum university students, Axum Town, North Ethiopia. BMC Public Health 2013, $13: 693$

[3] Numan N: The Green Leaf: Khat. World Journal of Medical Sciences2012; 7 (4): 210-223.

[4] Tesso G, Menon MKC, Gnanasekaran N and Seifu D: Effects of Crude Extract of Khat (Catha Edulis) On Liver Function in Rats: Cytotoxic and Haematalogical Studies. Int J Pharm Sci Res 2015; 6(8): 3254-59. doi: 10.13040/IJPSR.0975-8232.6 (8).3254-59.

[5] Kebede Y: Cigarette smoking and khat chewing among college students in North West Ethiopia. Ethiopian Journal of Health Development2002, 16:9-17.

[6] Abebe D, Debella A, Dejene A, Degefa A, Abebe A, Urga K, Ketema L:Khat chewing habit as a possible risk factor for HIV infection: A case-control study. Ethiopian Journal of Health Development 2005, 19:174-181.

[7] Seme A, Hailemariam D, Worku A: The association between substance abuse and HIV infection among people visiting HIV counseling and testing centers in Addis Ababa. Ethiopia. Ethiopian Journal of Health Development2005, 19:116-125.

[8] Kassaye M, Sherief TH, Ghimja F, Teklu F: Drug use among school students in Addis Ababa and Butajira. Ethiopian Journal of Health Development1999, 13:101-106.

[9] Kebede D, Alem A, Enquselassie F, Berhane F, Abebe Y, Ayele R, Lemma W, Assefa T, Gebremichael T: Khat and alcohol use and risky sex behavior among in-school and outof-school youth in Ethiopia. BMC Public Health2005, 5:109.

[10] Fekadu A, Atalay A and Charlotte H: Alcohol and Drug Abuse in Ethiopia: Past, Present and Future. African Journal of Drug
\& Alcohol Studies2007, 6(1):39-53.

[11] Deressa W and Azazh A: Substance use and its predictors among undergraduate medical students of Addis Ababa University in Ethiopia. BMC Public Health2011, 11:660.

[12] Kassa A, Tadesse F, Yilma A: Prevalence and factors determining psychoactive substance (PAS) use among Hawassa University (HU) undergraduate students, Hawassa Ethiopia. BMC Public Health 2014, 14:1044.

[13] Aklog A, Tiruneh G, Tsegay G: Assessment of Substance Abuse and Associated Factors among Students of Debre Markos Poly Technique College in Debre Markos Town, East Gojjam Zone, Amhara Regional State, Ethiopia, 2013. Global Journal of Medical research2013, Volume 13 Issue 4, USA.

[14] NASTAD-Ethiopia: HIV prevalence and associated factors among university students of Dire-Dawa University, eastern Ethiopia 2009.

https://wfpha.confex.com/wfpha/2012/web program/Paper9264.html. Accessed on February 21, 2014.

[15] Atwoli L, Mungla PA, Ndung'u MN, Kinoti KC, Ogot EM: Prevalence of substances use among college students in Eldoret, western Kenya. BMC Psychiatry 2011, 11:34.

[16] Girmay T and Ahmed E: Psychoactive Substances Use (Khat, Alcohol and Tobacco) and Associated Factors among Debre MarkosUniversity Students, North-West Ethiopia, 2013. J Def Manag 2014, 4: 118. doi:10.4172/2167-0374.1000118.

[17] Abrha T: Psychoactive Substance Abuse and Intention to Stop Among Students of Mekelle University, Ethiopia. Master's Thesis, Addis Ababa University, School of Public Health; 2011.

[18] Deressa W and Azazh A: Substance use and its predictors among undergraduate medical students of Addis Ababa University in Ethiopia. BMC Public Health2011, 11:660.

[19] Tsegay G, Esmael A: Psychoactive Substances Use (Khat, Alcohol and Tobacco) and Associated Factors among Debre Markos University Students, North-West Ethiopia. J DefManag 2014, 4:1.

[20] Haile D, Lakew Y: Khat Chewing Practice and Associated Factors among Adults in Ethiopia: Further Analysis Using the 2011 Demographic and Health Survey. PLOS ONE 2015, 10(6): e0130460. doi:10.1371/journal.pone.0130460.

[21] Ageely HM: Prevalence of Khat chewing in college and secondary (high) school students of Jazan region. SaudiArabia Harm Reduction J 2009, 6:11.

[22] Dida N, Kassa Y, Sirak T, Zerga E, Dessalegn T: Substance use and associated factors among preparatory school students in Bale Zone, Oromia Regional State, Southeast Ethiopia. Harm Reduction Journal 2014, 11:21.

[23] Mulugeta Y: Khat Chewing and Its Associated Factor among College Students in Bahir Dar Town, Ethiopia. Science Journal of Public Health 2013, Vol. 1, No. 5, pp. 209-214. doi: 10.11648/j.sjph.20130105.14.

[24] Reda AA, Moges A, Biadgilign S, Wondmagegn BY: Prevalence and Determinants of Khat (Catha edulis) Chewing among High School Students in Eastern Ethiopia: A Cross Sectional Study. PLoS ONE 2012, 7(3): $e 33946$. doi:10.1371/journal.pone.0033946. 
[25] Oshodi O, Aina O, Onajole A: Substances use among secondary school students in an urban setting in Nigeria: prevalence and associated factors. African J Psychiatry 2010, $13: 32-57$.
[26] Dida N, Kassa Y, Sirak T, Zerga E, Dessalegn T: Substance use and associated factors among preparatory school students in Bale Zone, Oromia Regional State, Southeast Ethiopia. Harm Reduction Journal 2014, 11:21. 